\title{
Progress Report on pH-Influenced Photocatalysis for Active Motion ${ }^{\dagger}$
}

\author{
Sandra Heckel ${ }^{1}$, Julia Hübner ${ }^{1}$, Anne Leutzgen ${ }^{2}$, Gregor Jung ${ }^{2}\left(\mathbb{D}\right.$ and Juliane Simmchen ${ }^{1, *}$ \\ 1 Physical Chemistry, Technische Universität Dresden, 01069 Dresden, Germany; \\ sandra.heckel@tu-dresden.de (S.H.); julia.huebner2@mailbox.tu-dresden.de (J.H.) \\ 2 Biophysical Chemistry, Saarland University, Campus, Geb. B2.2, 66123 Saarbrücken, Germany; \\ g.jung@mx.uni-saarland.de (G.J.) \\ * Correspondence: juliane.simmchen@tu-dresden.de \\ + In memory of Peter Grunwald.
}

Citation: Heckel, S.; Hübner, J.; Leutzgen, A.; Jung, G.; Simmchen, J. Progress Report on $\mathrm{pH}$-Influenced Photocatalysis for Active Motion. Catalysts 2021, 11, 599. https:// dx.doi.org/10.3390/catal11050599

Academic Editor: Nan Cheng

Received: 8 April 2021

Accepted: 28 April 2021

Published: 6 May 2021

Publisher's Note: MDPI stays neutral with regard to jurisdictional claims in published maps and institutional affiliations.

Copyright: (c) 2021 by the authors. Licensee MDPI, Basel, Switzerland. This article is an open access article distributed under the terms and conditions of the Creative Commons Attribution (CC BY) license (https:// creativecommons.org/licenses/by/ $4.0 /)$.

\begin{abstract}
Living systems use catalysis to achieve chemical transformations to comply with their needs in terms of energy and building blocks. The $\mathrm{pH}$ is a powerful means to regulate such processes, which also influences synthetic systems. In fact, the $\mathrm{pH}$ sensitivity of artificial photocatalysts, such as bismuth vanadate, bears the strong potential of flexibly influencing both the motion pattern and the speed of catalytic microswimmers, but it has rarely been investigated to date. In this work, we first present a comprehensive view of the motion behavior of differently shaped bismuth vanadate microswimmers, discuss influences, such as shape, $\mathrm{pH}$, and conductivity of the solutions, and find that the motion pattern of the swimmers switches between upright and horizontal at their point of zero charge. We then apply an immobilizable hydroxypyrene derivative to our substrates to locally influence the $\mathrm{pH}$ of the solution by excited-state proton transfer. We find that the motion pattern of our swimmers is strongly influenced by this functionalization and a third motion mode, called tumbling, is introduced. Taking other effects, such as an increased surface roughness of the modified substrates, into account, we critically discuss possible future developments.
\end{abstract}

Keywords: microswimmer; smart; pH-sensitive; photoacid

\section{Introduction}

In biology, the largest number of catalytic processes are performed by enzymes in aqueous solutions and, therefore, extremely sensitive to changes of $\mathrm{pH}$ in their environment. The possible $\mathrm{pH}$ effects on enzymes can either be inhibition or activation, acting via a variety of mechanisms and strategies, for example, by affecting the substrate binding. This has been described for invertase as early as 1911 [1].

Additionally, for artificial catalytic systems, it is known that the $\mathrm{pH}$ influences a variety of reactions: for example, in water splitting, developing well-performing catalysts for the hydrogen evolution reaction (HER) in a wide $\mathrm{pH}$ range is mechanistically important, because the HER elapses differently in acidic and alkaline media. Challenges therein are found to originate from electron transfer and redistribution at interfaces [2]. Additionally, the micro- and nanostructuring of these catalysts can have a large influence on their catalytic performance and provide a handle to influence the reaction that is not available for biological systems [3].

Most photocatalytically propelled artificial microswimmers use hydrogen peroxide $\left(\mathrm{H}_{2} \mathrm{O}_{2}\right)$ as fuel. When combined with a suitable photocatalyst and a light source, $\mathrm{H}_{2} \mathrm{O}_{2}$ is decomposed in a disproportionation reaction into water and oxygen (Equation (1)). The semiconductor thereby acts as a catalyst, which, upon illumination, provides separated electron-hole pairs to decrease the activation energy of the reaction.

$$
\mathrm{H}_{2} \mathrm{O}_{2} \rightarrow \mathrm{H}_{2} \mathrm{O}+1 / 2 \mathrm{O}_{2}
$$


The detailed course of this reaction is, to date, still a highly discussed topic [4,5]. It is known, that adsorption of $\mathrm{H}_{2} \mathrm{O}_{2}$ on the semiconductor surface leads to the formation of $\mathrm{OH}$ radicals which, in a chain reaction, form water and oxygen. Specifically in the neutral/acidic regime, a mechanism involving protons in the half reactions has been established as the most probable [6]. However, in alkaline solutions, the dissociation of $\mathrm{H}_{2} \mathrm{O}_{2}$, which leads to the formation of $\mathrm{HOO}^{-}$, has to be considered ( $\left.p K_{A, \mathrm{H}_{2} \mathrm{O}_{2}}=11.7\right)$. This changes the overall reaction (Equation (2)), also leading to an increased reaction rate $[7,8]$.

$$
\mathrm{H}_{2} \mathrm{O}_{2}+\mathrm{HOO}^{-} \rightarrow \mathrm{H}_{2} \mathrm{O}+\mathrm{O}_{2}+\mathrm{OH}^{-}
$$

In both of these scenarios, the decomposition of hydrogen peroxide will lead to the active propulsion of microswimmers, such as $\mathrm{TiO}_{2}$ or $\mathrm{BiVO}_{4}$. A comprehensive picture of the influence on $\mathrm{pH}$ and the fuel degradation mechanism is required in order to better understand the swimming behavior of microparticles in various environments, but analytical techniques for localized $\mathrm{pH}$ detection are still rare $[9,10]$. Despite the strong influence that might lead to better adaptation for specific tasks, most photocatalytic micromotion studies only present the behavior of the particles at neutral $\mathrm{pH}$ values.

In general, in order to achieve active motion, asymmetry in fuel degradation must be provided. If this is the case, propulsion is mainly caused by the two mechanisms of self-diffusiophoresis and self-electrophoresis.

In self-electrophoresis, the swimmer creates an electric field around itself, which causes the motion. On different locations of the charged swimmer surface, charged reaction products, like $\mathrm{H}^{+}$, are created. These ions migrate around the swimmer and drag fluid with them, which, in turn, leads to a net propulsion of the swimmer [11,12]. In self-diffusiophoresis, a gradient is believed to be created by the localized production of a neutral solute $\left(\mathrm{O}_{2}\right)$, which drives the motion [12]. However, it has been shown that neutral diffusiophoresis is rather unlikely when compared to an ionic mechanism, where the neutral reactants, like $\mathrm{H}_{2} \mathrm{O}_{2}$, are broken into ions first, so that this motion mechanism is also eventually dominated by self-electrophoresis $[13,14]$. It is apparent that a change in $\mathrm{pH}$ can dramatically influence these propulsion mechanisms. Here, we want to report our recent progress on $\mathrm{pH}$ modulated $\mathrm{BiVO}_{4}$ microswimmers that propel by the photocatalytic degradation of $\mathrm{H}_{2} \mathrm{O}_{2}$. We assume their motion mechanism to be dominated by ionic contributions, which leads to a mechanism influenced by an interplay of ionic self-diffusiophoresis and electrophoresis.

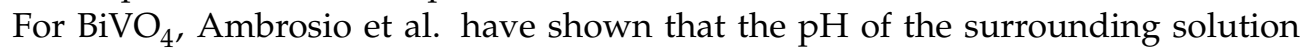
will influence which species is adsorbed to the catalyst surface, which, in turn, then also influences the course of the reaction $[15,16]$. Additionally, the identity of the produced ions should have an influence on the propulsion, as hydrogen ions have a mobility twice as high as hydroxide ions [17]. The increased reaction rate of hydrogen peroxide decomposition in alkaline media can also influence the swimmer propulsion speed. Dey et al. [18] has also demonstrated an example for this phenomenon. Polymer microparticles were covered with $\mathrm{Pd}$ nanobeads and immersed in a $5 \% \mathrm{H}_{2} \mathrm{O}_{2}$ solution. By imposing a $\mathrm{pH}$ gradient from neutral to alkaline in their solution, they observed two effects: firstly, swimmers moved at higher speeds in more alkaline solutions. Secondly, the swimmers showed $\mathrm{pH}$ taxis by following the gradient and navigating to the area with the highest $\mathrm{pH}$. They explain this behavior by the increased self-decomposition of $\mathrm{H}_{2} \mathrm{O}_{2}$ at alkaline $\mathrm{pH}$ values, inducing a pressure gradient on the swimmers. Recently, we reported $\mathrm{BiVO}_{4}$ microswimmers with adjustable motion patterns in solutions with different $\mathrm{pH}$ values [19]. The stacked, squareshaped microswimmers exhibit a $90^{\circ}$ rotation and upright motion at neutral/alkaline $\mathrm{pH}$ values, whereas, at acidic $\mathrm{pH}$ values lower than their point of zero charge (PZC) $\left(\mathrm{pH}_{\mathrm{PZC}}\left(\mathrm{BiVO}_{4}\right)=3.4\right)$, the swimmers perform horizontal motion with absence of a rotation upon activation [19]. To achieve more specific control over the particle motion, it is desirable to include a possibility to change the $\mathrm{pH}$ locally, so that the motion pattern of the same set of swimmers can be adjusted within the same solution. This way, the adjustable motion 
properties of these swimmers could be exploited to achieve rapid adjustment to changing conditions in their environment.

In this manuscript, we report our advances by modifying the substrates on which the microswimmers propel with a light-responsive hydroxypyrene derivative and achieve a localized influence on the solution $\mathrm{pH}$ by exciting the system with UV light. We investigate the influence of this functionalization on swimmer speed and motion pattern. By that, we aim to broaden the possible application range of these catalytic microswimmers into a $\mathrm{pH}$ range away from the neutral regime, where we want to contribute to the mechanistic understanding of $\mathrm{H}_{2} \mathrm{O}_{2}$ decomposition. Enabling $\mathrm{pH}$ as a handle to control microswimmer motion modes is a promising method for adjusting the swimmers propulsion to environmental conditions, as observed in many biological systems [20].

\section{Results and Discussion}

Bismuth vanadate microparticles were synthesized by a solvothermal procedure, as previously reported $[19,21]$. By adjusting the synthesis $\mathrm{pH}$ precisely to 2 or 3 before particle ripening, either spheroidal or rather square shaped particles can be redeemed, respectively. For both particle shapes, SEM images reveal a polycrystalline appearance of the particles, which indicates that larger microparticles form during the synthesis by assembly of smaller crystallites (see Figure 1a). While both of these particle shapes possess the same overall crystal structure (monoclinic scheelite), it can be seen that the square shaped particles show a kind of stacked structure, which indicates a certain orientation of the crystallites during the synthesis. This orientation of crystal facets in $\mathrm{BiVO}_{4}$ is well known and it leads to a spatial separation of electrons and holes in an excited state [22,23]. As we described in a previous work, this separation leads to an asymmetric fuel degradation gradient for these particles and, consequently, to active motion when illuminated in a diluted $\mathrm{H}_{2} \mathrm{O}_{2}$ solution (see Figure 1b) [19].

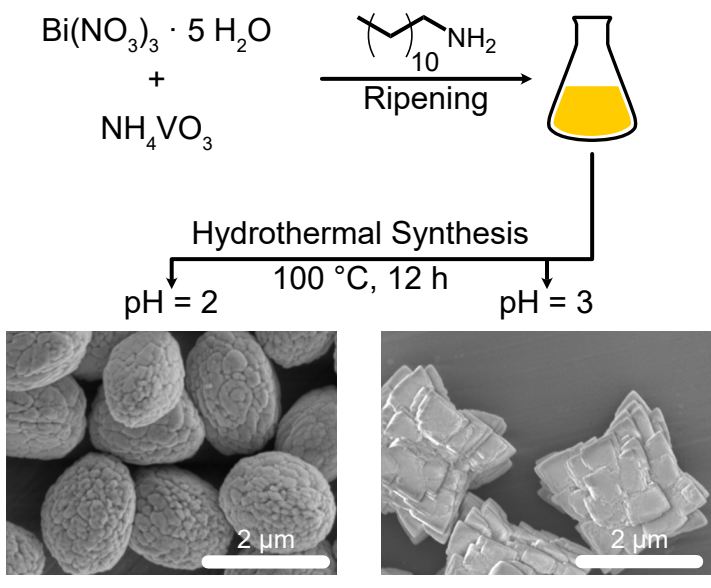

(a)

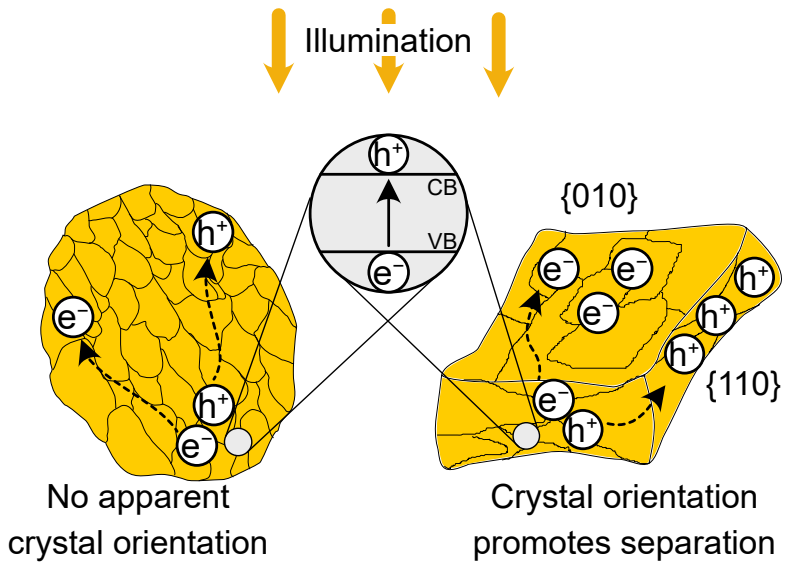

(b)

Figure 1. (a) Synthesis scheme of $\mathrm{BiVO}_{4}$ microparticles at $\mathrm{pH}=2$ and $\mathrm{pH}=3$, which results in spheroidal and square shaped particles, respectively. (b) Illumination of particles leads to the formation of excited electron-hole pairs, which, in the case of square shaped particles, are spatially separated due to inherent crystal orientation.

For the spheroidal particles, a clear trend in crystal orientation cannot be easily detected. However, in combination with self-shadowing effects [24], it may still contribute to a fuel gradient around the swimmer, as we also observe active motion for this kind of swimmers without further modification [21].

The motion pattern of these swimmers strongly depends on the $\mathrm{pH}$ value of their surrounding solution. Figure 2 illustrates this behavior for stacked square-shaped swimmers. Particle speed, motion modes, and zeta potential, together with conductivity of the solution, are displayed to give a comprehensive picture of the observed active motion. At $\mathrm{pH}$ values 
above the $\mathrm{BiVO}_{4} \mathrm{PZC}(\mathrm{pH}=3.4)$, over $95 \%$ of square shaped swimmers perform a $90^{\circ}$ upright rotation when excited, which we call upright sliding. It is likely that the spatial crystal orientation and electron/hole separation in combination with the unique stacked square shape of these swimmers leads to the formation of osmotic pressure between the substrate and particle, causing the upright rotation upon illumination. The mean speeds are mainly constant over the different $\mathrm{pH}$ values, except for a strong increase around $\mathrm{pH} 10$, which may be attributed to the increased reaction rate of $\mathrm{H}_{2} \mathrm{O}_{2}$ degradation in the alkaline regime. At even more alkaline conditions, the swimmer speed decreases again because of the increasing ion concentration in the solution. This may also lead to a small percentage of horizontal moving swimmers at $\mathrm{pH} 11$, for which the upright rotation is suppressed. At $\mathrm{pH}$ values that are lower than the PZC, a rotation upon illumination does not appear anymore, which leads to horizontal sliding as a motion mode. Additionally, the mean particle speeds are slightly decreased. This observation may be explained by a closer look at the catalysts surface and the adsorbed species. When working in neutral/alkaline media above the PZC, the particles obtain a negative zeta potential, with $\mathrm{H}_{2} \mathrm{O} / \mathrm{H}_{2} \mathrm{O}_{2}$ adsorbed to the surface, which is increasingly replaced by $\mathrm{OH}^{-}$and $\mathrm{OOH}^{-}$in the alkaline regime. Additionally, the superoxide radical $\mathrm{HO}_{2}{ }^{\circ}$, which is believed to be an important precursor for hydroxide radicals, is more easily adsorbed at alkaline $\mathrm{pH}$ values [15,25].
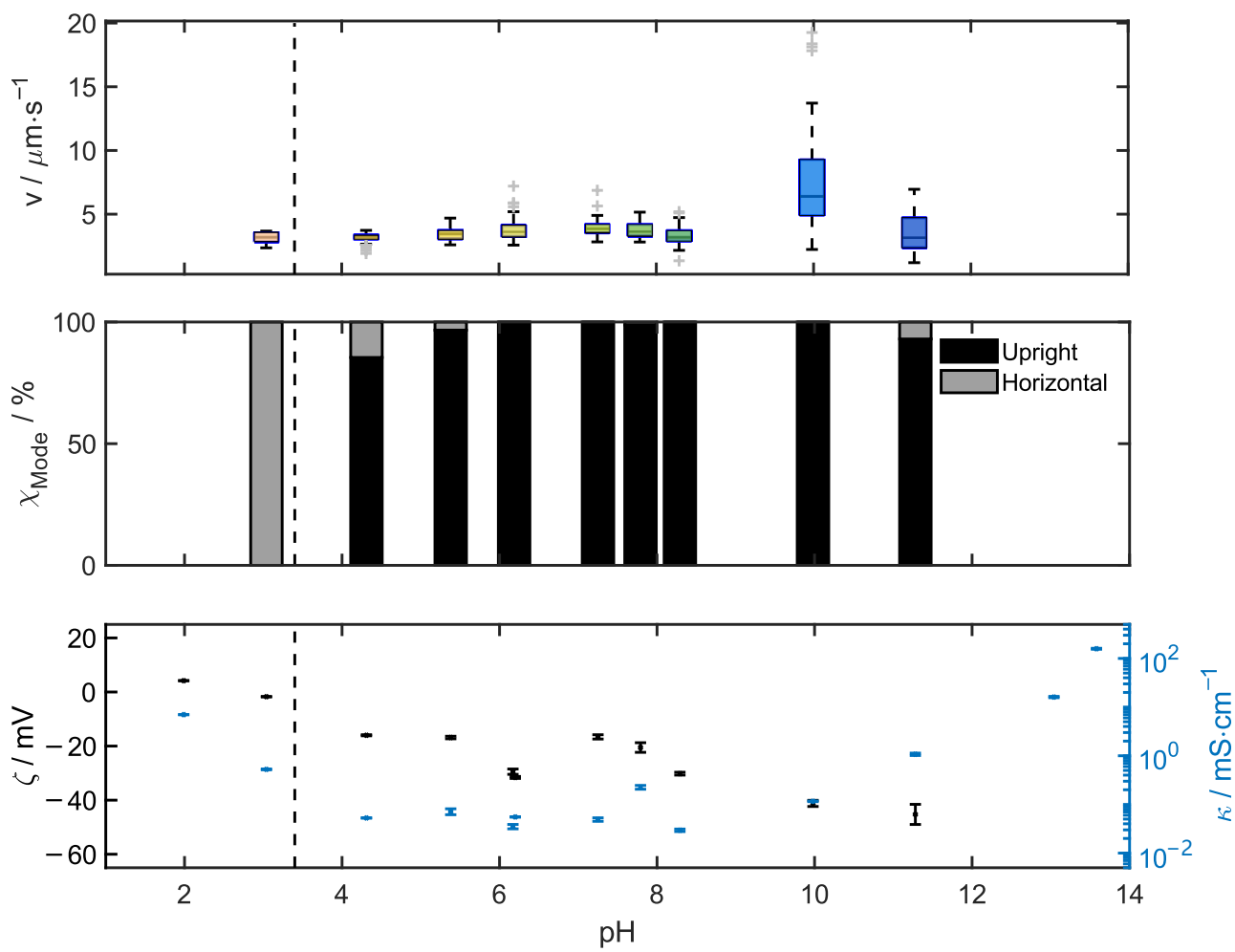

Figure 2. Motion characteristics of square-shaped swimmers at different $\mathrm{pH}$ values. First graph shows box plots for mean speed distributions (colors correspond to universal $\mathrm{pH}$ indicator color index, grey crosses represent outliers), second plot illustrates ratio between upright and horizontal motion at corresponding $\mathrm{pH}$, and the third plot shows the zeta potential of particles and conductivity of the solution. Dashed line marks the $\mathrm{pH}_{\mathrm{PZC}}=3.4$.

At $\mathrm{pH}$ values that are lower than the PZC, the surface of the particles is positively charged with hydrogen cations adsorbed to it [15]. This can lead to the formation of stabilized, hydrogen-bonded $\mathrm{H}_{2} \mathrm{O}_{2}$ clusters, preventing an efficient fuel degradation [25]. In consequence, lower mean particle speeds are observed. Additionally, it may be possible that this decreased catalyst activity may lead to the absence of an upright rotation upon illumination. 
For spheroidal particles, trends in the change of motion pattern as well as speed are less pronounced (see Figure S1). However, a change is also observed upon inversion of the catalysts surface charge. Here, the swimmers show no upright rotation in neutral/alkaline media and perform horizontal sliding. However, if the $\mathrm{pH}$ decreases below PZC, around $50 \%$ of the particles rotate by $90^{\circ}$ and move upright on their tips (see Video S1). The fact that only half of the swimmers exhibit a change in motion pattern may be attributed to the overall lower activity of these swimmers. Therefore, we decided to choose square shaped swimmers for further studies of local $\mathrm{pH}$ adjustment, as the effect is more pronounced for these particles and it should be possible to clearly detect the influence of a local $\mathrm{pH}$ change.

The influence of $\mathrm{pH}$, especially on the motion pattern, can potentially be exploited to adjust the swimmer behavior to external conditions. However, adjusting the $\mathrm{pH}$ by adding a concentrated acid or base to a microscopic sample will always change the conditions of the whole solution and inhibit the study of flexible motion changes when a swimmer moves from one set of conditions to another one, potentially inverting its zeta potential. Here, we expect that a more localized change in $\mathrm{pH}$ can lead to increased control over the swimmer behavior.

To achieve this, we functionalized glass substrates with an immobilizable hydroxypyrene derivative, a so-called photoacid. These aromatic molecules are weak acids in their ground state, but, upon excitation, their acidity constant $\left(\mathrm{p} K_{\mathrm{a}}^{*}\right)$ increases by several orders of magnitude. This enables excited-state proton transfer (ESPT) from the photoacid to a suitable acceptor, commonly the solvent. The photoacid in this work, 3,8-bis $(\mathrm{N}, \mathrm{N}-$ dimethylsulfamoyl)-6-hydroxypyrene-1-sulfonylchloride (HPDASCl), has a negative $\mathrm{p} K_{\mathrm{a}}^{*}$, which makes it a super-photoacid, i.e., bearing the ability to not only transfer a proton to water, but also to non-aqueous solvents, like methanol, dimelthylformaide, or dimethyl sulfoxide [26,27].

To study the behavior of immobilized HPDASCl, we adapted a method that was developed by Clasen et al. to bind the dye to silica microparticles (see Figure 3a). After functionalizing it with 3-aminopropyltriethoxysilane (APTES), it can then be bound to silica microparticles by a condensation reaction in alkaline media. Figure $3 b, c$ show the corresponding excitation and emission spectra of functionalized particles dispersed in deionized water. By modifying the solution $\mathrm{pH}$, which was achieved by the addition of trifluoroacetic acid and sodium hydroxide, excitation and emission features of the protonized ( $\mathrm{ROH})$ and deprotonized $\left(\mathrm{RO}^{-}\right)$form were obtained. For comparison, the spectra of the free HPDASCl-APTES under the same conditions can be found in Figure S2. The deprotonized form $\mathrm{RO}^{-}$commonly shows absorption and emission features at higher wavelengths than the protonized form $\mathrm{ROH}$. In Figure $3 b$, excitation spectra confirm the presence of a deprotonized form $\mathrm{RO}^{-}$with an excitation maximum at $454 \mathrm{~nm}$ between $\mathrm{pH} 11$ and 7. At increasingly acidic $\mathrm{pH}$ values, the absorption peak of the protonized form $\mathrm{ROH}$ at $406 \mathrm{~nm}$ becomes more pronounced. Emission was detected at $560 \mathrm{~nm}$ for all excitation spectra.

The emission spectra shown in Figure 3c only show one emission peak at $512 \mathrm{~nm}$, which can be assigned to the deprotonized form $\mathrm{RO}^{-}$. The protonated form $\mathrm{ROH}$ immediately deprotonates in excited state due to the highly increased acidic constant [27].

As the sample is excited at $365 \mathrm{~nm}$, where mainly the protonated form of the dye absorbs, samples with the lowest $\mathrm{pH}$ typically give the highest emission intensities. Indeed, this is observed for free HPDASCl-APTES (see Figure S2b), but the trend seems to be inversed here. The highest emission intensities are observed for rather alkaline samples, at which the dye is present in the $\mathrm{RO}^{-}$form and no ESPT takes place. This can be an indicator that the deprotonized form of the dye is more stable when bound to the silica matrix, even in alkaline media, yielding lower ESPT rates and, therefore, lower emission intensities.

Although the $\mathrm{pH}$ sensitivity is less pronounced for immobilized $\mathrm{HPDASCl}$ as compared to the free dye (see Figure S2), these spectra confirm its applicability in experiments with $\mathrm{pH}$ sensitive $\mathrm{BiVO}_{4}$ microswimmers. The absorption and emission maxima determined here are blue-shifted up to $43 \mathrm{~nm}$ as compared to the values obtained by Clasen et al., 
who first immobilized HPDASCl on silica nanoparticles (see Table S1) [28]. The reason for this difference most likely lays in the larger particle size used in this work as well as the different local environment caused by solvent composition, which makes comparison with literature values more difficult.
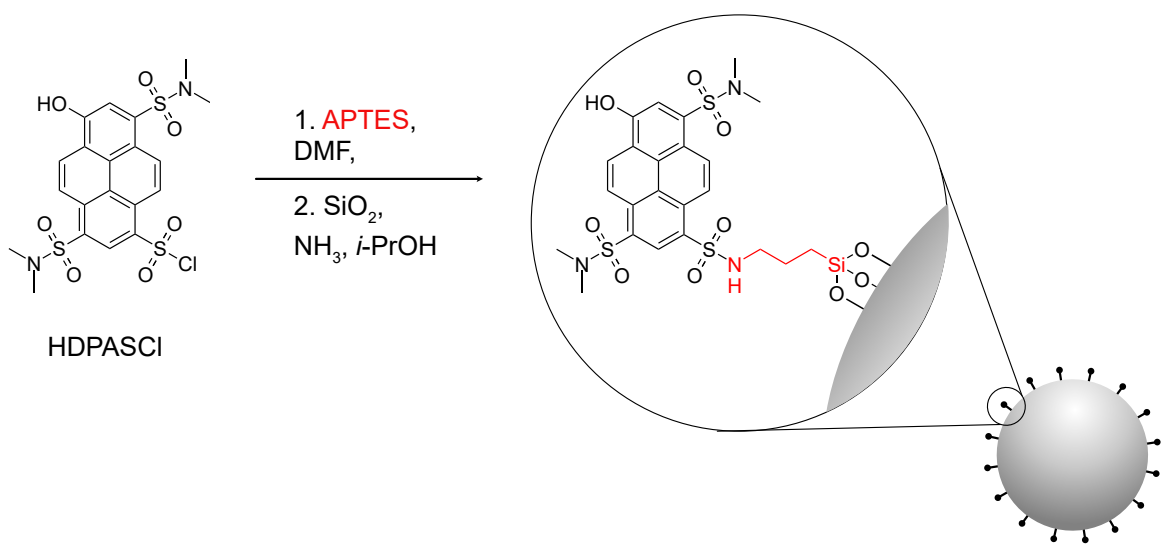

(a)

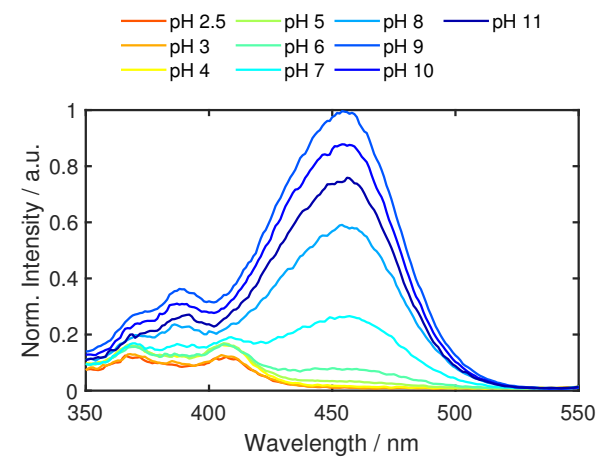

(b)

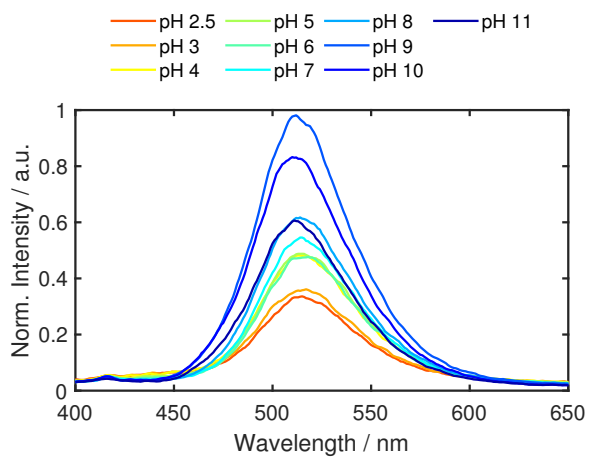

(c)

Figure 3. (a) Synthesis scheme for immobilization of $\mathrm{HPDASCl}$ on $\mathrm{SiO}_{2}$ microparticles in a two-step approach (b) Excitation spectra of functionalized particles, emission wavelength was set to $560 \mathrm{~nm}$ and (c) emission spectra of functionalized particles with excitation at $365 \mathrm{~nm}$.

For experiments with $\mathrm{BiVO}_{4}$ microswimmers, the photoacid had to be immobilized on glass substrates, which was achieved by the same two-step approach, as in Figure 3a, although the solution was in the second step dropcasted onto a clean glass substrate. The success of this method was evaluated by fluorescence microscopy of the modified substrates. The samples were excited with a $488 \mathrm{~nm}$ laser and fluorescence images were taken (see Figure S3). Figure 4a displays the mean grey value of these images versus the concentration of HPDASCl during functionalization. Concentrations of HPDASCl-APTES between $1.88 \times 10^{-8}$ to $1.41 \times 10^{-4} \mathrm{mmol} \cdot \mathrm{L}^{-1}$ were chosen. For substrates with even higher concentrations during functionalization, we observed that the microswimmers just stick to the substrate upon activation, which makes the observation of their motion impossible. For the data shown, the mean grey value increases linearly with the HPDASClAPTES concentration during functionalization over a large concentration interval of four orders of magnitude (see the blue trendline in Figure 4a). This provides a handle to easily adjust the overall dye concentration in the final substrate to the desired amount.

The functionalization with HPDASCl should be homogeneously distributed over the whole substrate in order to reliably control the swimming mode of the microswimmers. Especially at higher concentrations, fluorescence microscopy images show that this is not 
the case (see Figure S3). Instead, bright islands with high dye concentrations form. These islands also extend in the vertical axis, possibly posing obstacles to the swimmer motion.

In consequence, a third swimming mode, called tumbling, is observed when squareshaped $\mathrm{BiVO}_{4}$ microparticles are immersed in a diluted $\mathrm{H}_{2} \mathrm{O}_{2}$ solution and excited with UV light on these substrates. When a particle tumbles, it does not clearly propel in one motion mode over the whole illumination time, but repeatedly changes between upright and horizontal. Figure $4 \mathrm{~b}$ shows the swimming modes observed on substrates with different dye concentration. The UV excitation of $385 \mathrm{~nm}$ excites the semiconductor particles as well as the photoacid at the same time. The $\mathrm{pH}$ drop, which is caused by ESPT of the photoacid, should then influence the swimmer motion. To assess the influence, the observations here should be compared to the data at pH 6.2 shown in Figure 2, which is only different in terms of an unmodified substrate, but was otherwise done at the same conditions. There, all of the particles move in the upright orientation.

Undeniably, an influence on particle motion can be detected when modified substrates are used (see Video S2). Even for samples with a dye concentration during functionalization as low as $1.88 \times 10^{-8} \mathrm{mmol} \cdot \mathrm{L}^{-1}$, a non-negligible amount of horizontally swimming and tumbling microswimmers can be found, being higher than on unfunctionalized substrates at otherwise same conditions (see Figure 2). This observation strongly suggests an influence of the increased roughness of the samples by the aforementioned formation of silane islands on the substrates. Ideally, by increasing the dye concentration during functionalization, the influence of a $\mathrm{pH}$ drop during excitation should tune the motion mode of the microswimmers from mainly upright to horizontal. However, in the experiments, the effect is overlaid with the increase in surface roughness stemming from the silanization reaction used for coupling. Although the functionalization clearly has an effect on the swimmer motion and increases the percentage of horizontally moving particles to up to $46 \%$, this percentage does not increase linearly with increasing dye concentration.

Possibly, the inhomogeneous distribution of HPDASCl on the substrate cannot cause a constant influence on the local $\mathrm{pH}$. Additionally, the before shown effect of decreased ESPT for immobilized HPDASCl may be the reason for an insufficient $\mathrm{pH}$ drop. This may make the particles tumble and destabilize in their upright position, but not enough to consistently overcome the point of zero charge and switch to horizontal motion.

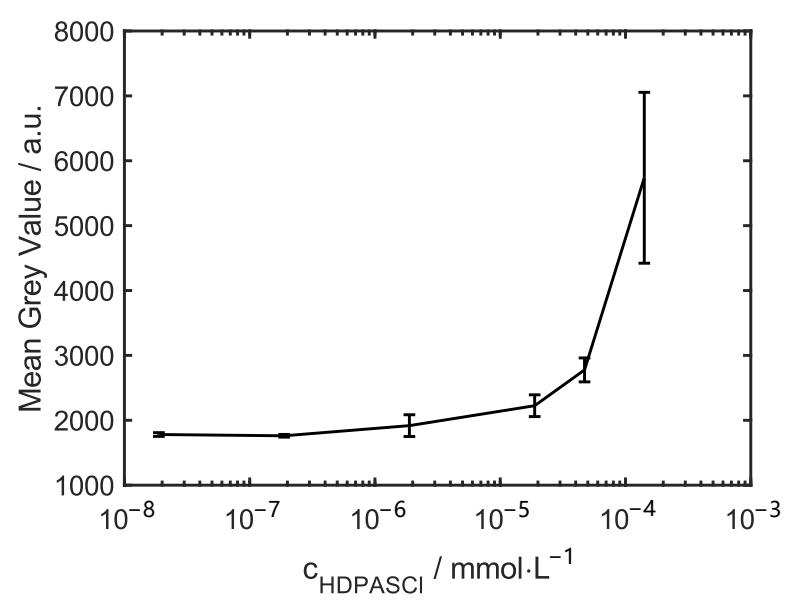

(a)

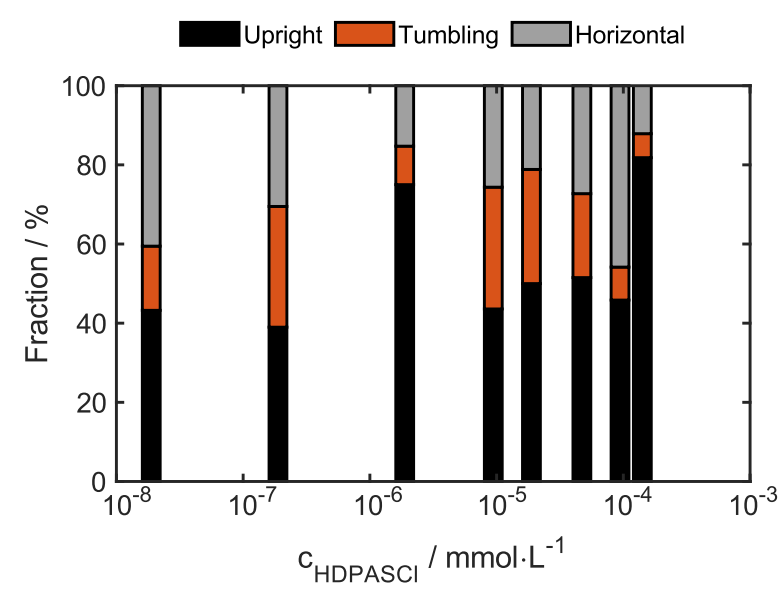

(b)

Figure 4. (a) Mean grey value of fluorescence microscopy images taken of substrates with increasing HPDASCl concentration during functionalization, blue line represents the linear trendline. (b) Motion modes of square-shaped particles on substrates with increasing dye concentration during illumination. The particles and HPDASCl were excited simultaneously by illumination with a $385 \mathrm{~nm}$ UV LED. 


\section{Materials and Methods}

\subsection{Synthesis of $\mathrm{BiVO}_{4}$ Microparticles}

Synthesis was performed after protocols published by Heckel et al. [19,21]. In an $100 \mathrm{~mL}$ Erlenmeyer flask, concentrated nitric acid $(2.5 \mathrm{~mL})$ was added to a 1:1 mixture of ethanol and ethylene glycol $(12.5 \mathrm{~mL})$. Next, dodecylamine $(2.78 \mathrm{~g}, 15 \mathrm{mmol})$ was added and dissolved under stirring. Afterwards, $\mathrm{Bi}\left(\mathrm{NO}_{3}\right)_{3}(2.425 \mathrm{~g}, 10 \mathrm{mmol})$ and $\mathrm{NH}_{4} \mathrm{VO}_{3}$ $(0.585 \mathrm{~g}, 10 \mathrm{mmol})$ were added under stirring. After dissolution, the $\mathrm{pH}$ was adjusted with a $2 \mathrm{M} \mathrm{NaOH}$ solution (in $\mathrm{H}_{2} \mathrm{O}$ :ethanol:ethylene glycol in a 0.5:1:1 ratio), and a brownish precipitate was formed. The $\mathrm{pH}$ was either adjusted to 2 (spheroidal particles) or 3 (square-shaped particles), depending on the desired particle shape. The solution was then transferred to a $50 \mathrm{~mL}$ Teflon-lined autoclave and left to ripen for $3 \mathrm{~h}$, which was then followed by a heat treatment at $100{ }^{\circ} \mathrm{C}$ for $12 \mathrm{~h}$. The particles were then carefully washed three times with ethanol and dried at $60^{\circ} \mathrm{C}$ for $12 \mathrm{~h}$.

\subsection{Synthesis of $\mathrm{SiO}_{2}$ Particles and HPDASCl Immobilization}

$\mathrm{SiO}_{2}$ particles were synthesized by an adjusted Stöber approach after Iojima et al. [29]. In a three-necked flask, $11.722 \mathrm{~mL}$ tetraethylorthosilicate, $13.237 \mathrm{~mL} 25 \mathrm{wt} \% \mathrm{NH}_{4} \mathrm{OH}$, and $125 \mathrm{~mL} i$-PrOH were heated to $40{ }^{\circ} \mathrm{C}$ for $1 \mathrm{~h}$ under reflux. Afterwards, the dispersion was centrifuged and the supernatant was discarded. The redeemed particles were sonicated in $6 \mathrm{wt} \% \mathrm{HCl}$ for $1 \mathrm{~h}$ to remove excess ammonia and then washed extensively with deionized water. Afterwards, the particles were dried overnight at $80^{\circ} \mathrm{C}$.

For functionalization, HPDASCl was first coupled to 3-(aminopropyl)triethoxysilane (APTES), $1.78 \mathrm{mg} \mathrm{HPTASCl}$ were dissolved in $995 \mu \mathrm{L}$ dimethylformamide and $2.5 \mu \mathrm{L}$ APTES together with $0.5 \mu \mathrm{L}$ triethylamine werde added. The solution was stirred at $100 \mathrm{rpm}$ for $20 \mathrm{~min}$. The, $10 \mathrm{mg} \mathrm{SiO}$ microparticles were dispersed in $10 \mathrm{~mL} i-\mathrm{PrOH}$ and $1.5 \mathrm{~mL}$ of $25 \mathrm{wt} \% \mathrm{NH}_{4} \mathrm{OH}$, together with $100 \mu \mathrm{L}$ of APTES-coupled HPDASCl, was added. The solution was stirred at room temperature over night under the exclusion of light. The functionalized particles were then centrifuged and washed with ethanol extensively. The particles were redispersed in $500 \mu \mathrm{L}$ of ethanol and stored at $5{ }^{\circ} \mathrm{C}$ in amber vials.

\subsection{Immobilization of HPDASCl on Glass Substrates}

Glass substrates were cleaned by immersing them in a 5:1:1 mixture of deionized water, $25 \mathrm{wt} \% \mathrm{NH}_{4} \mathrm{OH}$ and $30 \mathrm{wt} \% \mathrm{H}_{2} \mathrm{O}_{2}$. Deionized water was first heated to a temperature of $50{ }^{\circ} \mathrm{C}$ in a water bath, then $\mathrm{NH}_{4} \mathrm{OH}$ was added. At $60{ }^{\circ} \mathrm{C}, \mathrm{H}_{2} \mathrm{O}_{2}$ was added dropwise. After $1 \mathrm{~min}$., glass substrates were immersed in the solution for $20 \mathrm{~min}$. Afterwards, they were excessively cleaned with deionized water and then dried under pressured air.

$1.25 \mu \mathrm{L}$ 3-(aminopropyl)triethoxysilane and $0.5 \mu \mathrm{L}$ triethylamine were added to an aliquote of $0.89 \mathrm{mg} \mathrm{HPTASCl}$ in $498 \mu \mathrm{L} i$-PrOH and stirred at RT for $45 \mathrm{~min}(100 \mathrm{rpm})$. The solution was then diluted with $i-\mathrm{PrOH}$ to redeem the desired dye concentration and then applied to the glass substrates.

\subsection{Zeta Potential and $\mathrm{pH}$ Measurements}

Measurements of zeta potential, conductivity, and $\mathrm{pH}$ were conducted with a Malvern Zetasizer Nano ZSP. Therefore, scaled up aqueous solutions with the same water/hydrogen peroxide ratio as used for microscopy were prepared and combined with $\mathrm{BiVO}_{4}$ microparticles. After measurement of the $\mathrm{pH}, 1 \mathrm{~mL}$ of the corresponding solutions was transferred to a zeta cell and zeta potential and conductivity were measured.

\subsection{Photoluminescence Spectroscopy}

Excitation and emission spectra were recorded on a FluoroMax 4 spectrofluorometer (HORIBA Jobin YVON Inc., Edison, NJ, USA). Therefore, $40 \mu \mathrm{L}$ of free HPDASCl-APTES or particle suspension were immersed in $1 \mathrm{~mL}$ water and then measured in a quarz cuvette. For the excitation spectra, the emission wavelength was set to $560 \mathrm{~nm}$. An excitation wavelength of $365 \mathrm{~nm}$ was used for emission spectra. TFA or $\mathrm{NaOH}$ was added in the 
quarz cuvette while measuring the $\mathrm{pH}$ value of the solution to obtain different $\mathrm{pH}$-values. The spectra were corrected for the thereby caused dilution of the dye in post-processing.

\subsection{Scanning Electron Microscopy}

For SEM imaging, diluted solutions of $\mathrm{BiVO}_{4}$ microparticles were dropcasted on aluminum tape-coated sample holders and dried overnight. The images were obtained using a Zeiss Ultra Gemini electron microscope.

\subsection{Fluorescence Microscopy of Functionalized Substrates}

Substrates with immobilized HPDASCl were imaged in a Nikon Ti-E STORM fluorescence microscope with a 100X oil immersion objective. Therefore, a droplet of deionized water was added to the substrates prior to imaging with a $488 \mathrm{~nm}$ laser.

\subsection{Light Microscopy}

For experiments at different $\mathrm{pH}$, aqueous solutions at $\mathrm{pH}$ values between 2 and 13 were prepared from concentrated hydrochloric acid and sodium hydroxide pellets in $50 \mathrm{~mL}$ measuring flasks. For the experiment, a few milligram of $\mathrm{BiVO}_{4}$ particles were dispersed in $1 \mathrm{~mL}$ aqueous solution of a certain $\mathrm{pH}$ by ultrasonification for $3 \mathrm{~min}$. Subsequently, $9 \mu \mathrm{L}$ of the solution was mixed with $1 \mu \mathrm{L} 1 \% \mathrm{H}_{2} \mathrm{O}_{2}$ and the particle motion was observed in the microscope. Sample illumination was performed with a flexible Colibri 7 light source of $385 \mathrm{~nm}$. The experiments were usually done under 50\% illumination intensity, where $100 \%$ corresponds to $315 \mathrm{~mW}$. The videos were evaluated with ImageJ and a Matlab, which use the Trackmate plugin [30] and the msdanalyzer [31] package, respectively.

\section{Conclusions}

To summarize, we have presented a comprehensive overview of the motion modes of photocatalytic $\mathrm{BiVO}_{4}$ microswimmers at different $\mathrm{pH}$ values. It was shown that the particle speeds increase specifically in the alkaline $\mathrm{pH}$ regime due to a higher rate constant of $\mathrm{H}_{2} \mathrm{O}_{2}$ decomposition $[7,8]$. When the zeta potential of these swimmers changes from negative to positive at $\mathrm{pH}=3.4$, their motion pattern changes. This effect is especially pronounced for square-shaped swimmers, which switch from an upright to a horizontal motion pattern. In order to exploit this adjustable swimming behavior, we used an immobilizable hydroxypyrene derivative, the photoacid HPDASCl, which can locally change the $\mathrm{pH}$ of the solution by excited-state proton transfer.

HPDASCl was successfully immobilized on silica microparticles and glass substrates; however, its distribution on the substrates showed to be highly heterogenous. This resulted in the formation of fluorescent silane islands on the glass substrates. When immersing $\mathrm{BiVO}_{4}$ microswimmers on these substrates and exciting them as well as the photoacid with UV light, an influence on the motion pattern could be detected. When compared to particles on unfunctionalized substrates, we observed a third motion mode, which we call tumbling. We also observed a higher degree of horizontally moving swimmers; however, no clear trend, depending on the dye concentration in the substrate, was obvious. This may be due to the inhomogeneous distribution of the dye or decreased ESPT in the immobilized state. To follow up on these promising results and move towards a spatially resolved control, future work will combine topologically structured surfaces with photoacids, which can be controlled by light patterns that are caused by wavelengths that are not influenced by the irradiation used for propulsion.

Supplementary Materials: The following are available online at https:/ / www.mdpi.com/article/10 .3390 / catal11050599/s1, Figure S1: Motion modes, speeds and zeta potentials of spheroidal $\mathrm{BiVO}_{4}$ swimmers at different $\mathrm{pH}$ values, Figure S2: Excitation and emission spectra of free HDPASCl-APTES in water, Table S1: Excitation and emission maxima of HPDASCl-APTES immobilized on SiO2 microparticles $(d=463 \pm 29 \mathrm{~nm})$ in this work and for Clasen et al. 
Author Contributions: Conceptualization, J.S. and S.H.; methodology, J.S., S.H. and G.J.; software, S.H. and J.H.; validation, S.H., J.H., G.J. and J.S.; formal analysis, J.H. and S.H.; investigation, J.H. and S.H.; resources, J.S., A.L. and G.J.; data curation, S.H. and J.H.; writing-original draft preparation, S.H. and J.H.; writing-review and editing, S.H. and J.S.; visualization, S.H.; supervision, J.S.; project administration, J.S.; funding acquisition, J.S. All authors have read and agreed to the published version of the manuscript.

Funding: This research was funded by a Freigeist grant (No 91619) from the Volkswagen foundation.

Data Availability Statement: Data is contained within the article or Supplementary Material.

Acknowledgments: The Fluorescence intensity measurement was performed on a Nikon Ti-E STORM fluorescence microscope of the Molecular Imaging and Manipulation Facility, a core facility of the CMCB at Technische Universität Dresden. We acknowledge the introduction by Jens Ehrig. Open Access Funding by the Publication Fund of the TU Dresden.

Conflicts of Interest: The authors declare no conflict of interest.

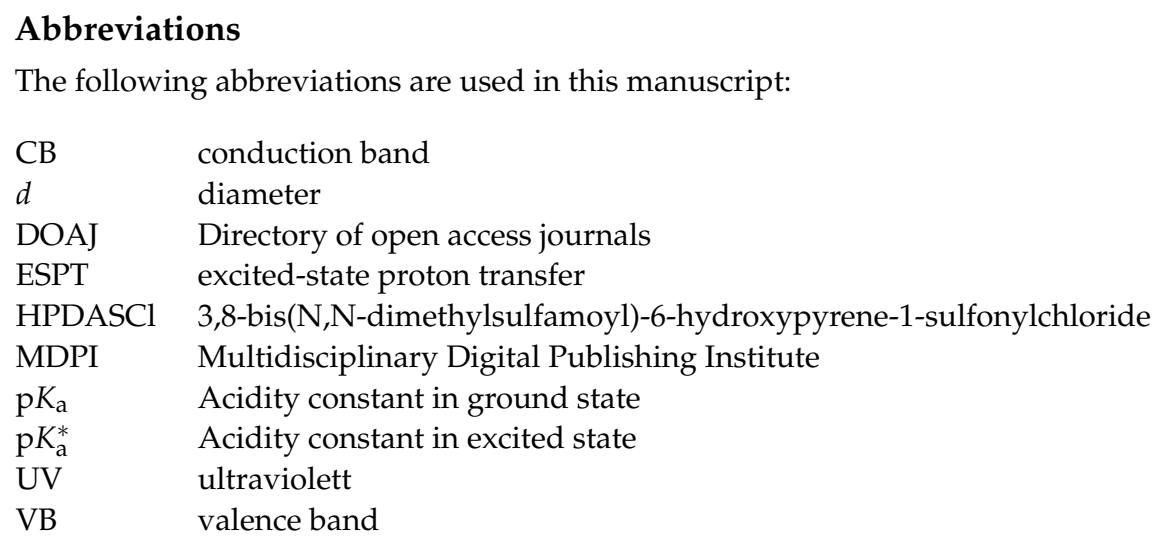

\section{References}

1. Michaelis, L.; Pechstein, H. Die Wirkungsbedingungen der Speicheldiastase. Biochem. Z. 1914, 59, 77-99.

2. Luo, Y.; Tang, L.; Khan, U.; Yu, Q.; Cheng, H.M.; Zou, X.; Liu, B. Morphology and surface chemistry engineering toward $\mathrm{pH}$-universal catalysts for hydrogen evolution at high current density. Nat. Commun. 2019, 10, 269. [CrossRef] [PubMed]

3. Zhang, K.; Fraxedas, J.; Sepulveda, B.; Esplandiu, M.J. Photochemically Activated Motors: From Electrokinetic to Diffusion Motion Control. ACS Appl. Mater. Interfaces 2017, 9, 44948-44953. [CrossRef] [PubMed]

4. Yi, J.; Bahrini, C.; Schoemaecker, C.; Fittschen, C.; Choi, W. Photocatalytic decomposition of $\mathrm{H}_{2} \mathrm{O}_{2}$ on different TiO ${ }_{2}$ surfaces along with the concurrent generation of $\mathrm{HO}_{2}$ radicals monitored using cavity ring down spectroscopy. J. Phys. Chem. C 2012, 116, 10090-10097. [CrossRef]

5. Hirakawa, T.; Yawata, K.; Nosaka, Y. Photocatalytic reactivity for $\mathrm{O}_{2}{ }^{-}$and $\mathrm{OH}$ - radical formation in anatase and rutile $\mathrm{TiO}_{2}$ suspension as the effect of $\mathrm{H}_{2} \mathrm{O}_{2}$ addition. Appl. Catal. A Gen. 2007, 325, 105-111. [CrossRef]

6. Shiraishi, Y.; Ueda, Y.; Soramoto, A.; Hinokuma, S.; Hirai, T. Photocatalytic hydrogen peroxide splitting on metal-free powders assisted by phosphoric acid as a stabilizer. Nat. Commun. 2020, 11, 1-9. [CrossRef]

7. Nicoll, W.D.; Smith, A.F. Stability of Dilute Alkaline Solutions of Hydrogen Peroxide. Ind. Eng. Chem. 1955, 47, 2548-2554. [CrossRef]

8. Duke, F.R.; Haas, T.W. The homogeneous base-catalyzed decomposition of hydrogen peroxide. J. Phys. Chem. 1961, 65, 304-306. [CrossRef]

9. Niu, R.; Khodorov, S.; Weber, J.; Reinmüller, A.; Palberg, T. Large scale Micro-Photometry for high resolution pH-characterization during electro-osmotic pumping and modular micro-swimming. arXiv 2017, arXiv:1708.02003.

10. Farniya, A.A.; Esplandiu, M.J.; Reguera, D.; Bachtold, A. Imaging the proton concentration and mapping the spatial distribution of the electric field of catalytic micropumps. Phys. Rev. Lett. 2013, 111, 1-5. [CrossRef]

11. Paxton, W.F.; Sundararajan, S.; Mallouk, T.E.; Sen, A. Chemical locomotion. Angew. Chem. Int. Ed. 2006, 45, 5420-5429. [CrossRef]

12. Moran, J.L.; Posner, J.D. Phoretic Self-Propulsion. Annu. Rev. Fluid Mech. 2017, 49, 511-540. [CrossRef]

13. Brown, A.; Poon, W. Ionic effects in self-propelled Pt-coated Janus swimmers. Soft Matter 2014, 10, 4016-4027. [CrossRef]

14. Brown, A.; Poon, W.C.; Holm, C.; De Graaf, J. Ionic screening and dissociation are crucial for understanding chemical selfpropulsion in polar solvents. Soft Matter 2017, 13, 1200-1222. [CrossRef]

15. Ambrosio, F.; Wiktor, J.; Pasquarello, A. PH-Dependent Surface Chemistry from First Principles: Application to the BiVO $4(010)-$ Water Interface. ACS Appl. Mater. Interfaces 2018, 10, 10011-10021. [CrossRef] 
16. Ambrosio, F.; Wiktor, J.; Pasquarello, A. pH-Dependent Catalytic Reaction Pathway for Water Splitting at the $\mathrm{BiVO}_{4}-\mathrm{Water}$ Interface from the Band Alignment. ACS Energy Lett. 2018, 3, 829-834. [CrossRef]

17. Lee, S.H.; Rasaiah, J.C. Proton transfer and the mobilities of the $\mathrm{H}^{+}$and $\mathrm{OH}^{-}$ions from studies of a dissociating model for water. J. Chem. Phys. 2011, 135, 124505. [CrossRef]

18. Dey, K.K.; Bhandari, S.; Bandyopadhyay, D.; Basu, S.; Chattopadhyay, A. The pH taxis of an intelligent catalytic microbot. Small 2013, 9, 1916-1920. [CrossRef]

19. Heckel, S.; Simmchen, J. Photocatalytic $\mathrm{BiVO}_{4}$ Microswimmers with Bimodal Swimming Strategies. Adv. Intell. Syst. 2019, 1, 1900093. [CrossRef]

20. Hintsche, M.; Waljor, V.; Großmann, R.; Kühn, M.J.; Thormann, K.M.; Peruani, F.; Beta, C. A polar bundle of flagella can drive bacterial swimming by pushing, pulling, or coiling around the cell body. Sci. Rep. 2017, 7, 16771. [CrossRef]

21. Heckel, S.; Grauer, J.; Semmler, M.; Gemming, T.; Löwen, H.; Liebchen, B.; Simmchen, J. Active assembly of spheroidal photocatalytic $\mathrm{BiVO}_{4}$ microswimmers. Langmuir 2020, 36, 12473-12480. [CrossRef]

22. Li, R.; Zhang, F.; Wang, D.; Yang, J.; Li, M.; Zhu, J.; Zhou, X.; Han, H.; Li, C. Spatial separation of photogenerated electrons and holes among $\{010\}$ and $\{110\}$ crystal facets of $\mathrm{BiVO}_{4}$. Nat. Commun. 2013, 4, 1432-1437. [CrossRef]

23. Li, R.; Han, H.; Zhang, F.; Wang, D.; Li, C. Highly efficient photocatalysts constructed by rational assembly of dual-cocatalysts separately on different facets of $\mathrm{BiVO}_{4}$. Energy Environ. Sci. 2014, 7, 1369-1376. [CrossRef]

24. Uspal, W.E. Theory of light-activated catalytic Janus particles. J. Chem. Phys. 2019, 150. [CrossRef]

25. Lousada, C.M.; Jonsson, M. Kinetics, mechanism, and activation energy of $\mathrm{H}_{2} \mathrm{O}_{2}$ decomposition on the surface of $\mathrm{ZrO}$. J. Phys. Chem. C 2010, 114, 11202-11208. [CrossRef]

26. Finkler, B.; Spies, C.; Vester, M.; Walte, F.; Omlor, K.; Riemann, I.; Zimmer, M.; Stracke, F.; Gerhards, M.; Jung, G. Highly photostable "super"-photoacids for ultrasensitive fluorescence spectroscopy. Photochem. Photobiol. Sci. 2014, 13, 548-562. [CrossRef]

27. Clasen, A.; Wenderoth, S.; Tavernaro, I.; Fleddermann, J.; Kraegeloh, A.; Jung, G. Kinetic and spectroscopic responses of pH-sensitive nanoparticles: Influence of the silica matrix. RSC Adv. 2019, 9, 35695-35705. [CrossRef]

28. Clasen, A.C. Immobilisierbare Pyrenderivate zur Anwendung als pH-Sonde. Ph.D. Thesis, Saarland University, Saarbrücken, Germany, 2019.

29. Isojima, T.; Lattuada, M.; Vander Sande, J.B.; Hatton, T.A. Reversible Clustering of pH- and Temperature-Responsive Janus Magnetic Nanoparticles. ACS Nano 2008, 2, 1799-1806. [CrossRef]

30. Tinevez, J.Y.; Perry, N.; Schindelin, J.; Hoopes, G.M.; Reynolds, G.D.; Laplantine, E.; Bednarek, S.Y.; Shorte, S.L.; Eliceiri, K.W. TrackMate: An open and extensible platform for single-particle tracking. Methods 2017, 115, 80-90. [CrossRef]

31. Tarantino, N.; Tinevez, J.Y.; Crowell, E.F.; Boisson, B.; Henriques, R.; Mhlanga, M.; Agou, F.; Israël, A.; Laplantine, E. Tnf and il-1 exhibit distinct ubiquitin requirements for inducing NEMO-IKK supramolecular structures. J. Cell Biol. 2014, 204, 231-245. [CrossRef] 